\title{
Developing an Acute Care Simulation Lab and Practicum
}

\author{
Erin Clark \\ Indiana University of Pennsylvania, eclark@iup.edu \\ Lori Lombard \\ Indiana University of Pennsylvania, Ilombard@iup.edu \\ DOI: https://doi.org/10.30707/TLCSD4.3/FXAP4522
}

Follow this and additional works at: https://ir.library.illinoisstate.edu/tlcsd

Part of the Speech Pathology and Audiology Commons

\section{Recommended Citation}

Clark, Erin and Lombard, Lori (2020) "Developing an Acute Care Simulation Lab and Practicum," Teaching and Learning in Communication Sciences \& Disorders: Vol. 4: Iss. 3, Article 5.

DOI: https://doi.org/10.30707/TLCSD4.3/FXAP4522

Available at: https://ir.library.illinoisstate.edu/tlcsd/vol4/iss3/5

This Scholarly Teaching is brought to you for free and open access by ISU ReD: Research and eData. It has been accepted for inclusion in Teaching and Learning in Communication Sciences \& Disorders by an authorized editor of ISU ReD: Research and eData. For more information, please contact ISUReD@ilstu.edu. 


\title{
Developing an Acute Care Simulation Lab and Practicum
}

\begin{abstract}
The benefits of simulation-based education have been well-documented in health-related disciplines and are emerging in speech-language pathology. Several clinical training paradigms for acute care speechlanguage pathology skills have been successful when implemented in high fidelity, nursing simulation labs with price tags that are cost prohibitive for most speech-language pathology programs. Through funding support from a grant and a four-phased simulation development program, the authors developed an acute care simulation lab dedicated to speech-language pathology students for under $\$ 9,000$ and simultaneously piloted a one-credit, acute care, adult- and geriatric-focused clinical practicum course. The clinical practicum was structured to scaffold student learning using task trainers, computer-based simulations, and live simulations with low fidelity manikins and standardized patients. The authors are hopeful that this article provides speech-language pathology programs a practical framework for structuring a dedicated, simulation space and course, while empowering faculty to more fully integrate simulation-based learning experiences into their curricula in a way that is evidence-based and in keeping with the best practice resources that are currently available in the field of speech-language pathology.
\end{abstract}


Since the American Speech-Language-Hearing Association (ASHA) approved the inclusion of simulation hours in 2016 (Council for Clinical Certification in Audiology and Speech-Language Pathology [CFCC], 2014), simulation has yet to be fully integrated into many speech-language pathology (SLP) curricula. More specifically, integration of adult and geriatric, acute care focused simulations has been particularly limited due to the lack of availability of such content in commercially-produced, computer-based simulations; restricted access to manikin-based opportunities in university nursing labs; as well as faculty inexperience in simulation methods. Furthermore, academic programs often lack the fiscal means to construct simulation labs dedicated to SLP clinical training. The purpose of this paper is to describe an approach to developing a simulation program with cost-effective infrastructure and a scaffolded curriculum dedicated to the acute care scope of practice in speech-language pathology.

\section{Simulation}

Across the literature available in several healthcare disciplines, simulation has many definitions. However, critical characteristics of simulation emerge regardless of the discipline: guided experience (Rothgeb, 2008; Carter, 2019) in situations that replicate, to various degrees, the reality of the clinical environment (Jeffries, 2005) for the purpose of experiential learning, dedicated practice, and assessment of competency outcomes (Lopreiato, 2016). As such, simulation-based education has emerged as accepted teaching methodology within many healthcare-related disciplines to include nursing (Lapkin et al., 2010; Brannan et al., 2008), pharmacy (Seybert, 2011), otolaryngology (Weit, 2011), and anesthesiology (Holzman et al., 1995), to name a few. As a tool for student training, simulation has been validated as efficacious and is regarded as innovative (Cook et al., 2011; Burns, 2010).

Effective learning in simulation relies on collaborative instructional practices among facilitators and students during a well-designed simulation exercise with measurable outcomes. The facilitator manages the design, instruction and execution of the simulation. In SLP, the role would need to be performed by a licensed and certified speech-language pathologist with a minimum of $25 \%$ student supervision (CFCC, 2020). The design of the simulation typically occurs in three phases: prebrief (i.e., introduction), scenario (i.e., context or case) and debrief (i.e., guided reflection) (Jeffries, 2005). The debriefing phase is often considered to have the most impact on learning. In a systematic review of 109 experimental studies in clinical education that span 34 years, authors identified features of high-fidelity simulated experiences that led to effective learning (Issenberg et al., 2005). The most salient feature of effective learning, found in $47 \%$ of the reviewed studies, was feedback from the facilitator during the debriefing phase. Repeated practice and integration of the simulations into the curriculum were the next most frequently reported characteristics at $39 \%$ and $25 \%$, respectively. Authors also identified aspects reported with lower incidence, such as active learning with multiple learning strategies, well-defined learning outcomes, and a range of difficulty levels for scenarios. Despite their lower incidence, all features were found to contribute to effective learning.

The efficacy of simulated learning environments in healthcare has led to growth in the industry. Innovative technologies and techniques are now available in multiple simulation modalities. Computer-based simulations and virtual reality products are digitizing 3-dimensional models of anatomy and clinical procedures. Wearable technologies, such as artificial airways and chest 
tubes, are readily available for simulated patients. Fidelity enhancements in scenarios specific to a wide range of healthcare disciplines are possible with advances in products that replicate operational medical accessories from surgical tools and medications to electronic health records. In addition, manikins are becoming less costly despite more technological sophistication with digital programming (Sanko, 2017). From professional education opportunities at conferences to academic certificates offered by universities, growth is even occurring in simulation education opportunities for facilitators. These rapidly advancing trends explain why healthcare simulation is currently estimated to be a $\$ 2$ billion industry (Sanko, 2016).

Increased availability and decreased costs of simulation technology does not mean that high fidelity simulation is a cost-effective instructional technology. Evidence is inconsistent and scant for reported cost-benefit ratios of developing an academic simulation program (Zendejas et al., 2013). Costs of equipment and technology vary by discipline with nursing programs requiring manikins with much more biometric sophistication than SLP students would require. Finding cost efficiencies in simulation labs is essential to program sustainability, especially if investing in high fidelity equipment (Eliadis \& Verkuyl, 2019). Eliadis and Verkuyl offered several strategies to balance a simulation center budget, such as reusing disposable materials, harvesting replacement parts for manikins, staffing labs with student workers, and renting the simulation space to other users. However, the return on investment for simulation labs is still difficult to determine considering the expendable materials, maintenance costs, faculty training expenses and tuitionbased income (Mahoney \& Haines, 2016).

Beyond the ambiguities of cost effectiveness in simulation training come the uncertainties of how much to implement this innovative teaching tool as a substitute for clinical practice. Experiential learning in an actual clinical setting is true fidelity and can offer ideal opportunities for all aspects of professional development. However, given the existing evidence base in simulation efficacy, perhaps the ethics of practicing on patients deserves reconsideration (Issenberg \& Scalese, 2008), at least in the early stages of acute care clinical training. Further, the challenge of finding supervised clinical placements offers academic programs a practical rationale for use of simulated learning environments. In addition, as healthcare disciplines shift to competency-based outcomes for credentialing (Gonczi, 2013), the ability to standardize clinical competency assessments with simulation becomes appealing. But, what percentage of clinical training should happen in a simulated learning environment?

Quantification of the appropriate proportion of simulation substitutions for clinical practice in healthcare education varies among disciplines. The National Council of State Boards of Nursing conducted a randomized controlled trial that indicated $50 \%$ of clinical hours in nursing can be replaced with high quality simulations without a negative impact on competency outcomes (Hayden et al., 2014). A systematic review of ten experimental studies from three different health professions identified direct simulation substitutions for clinical practice that ranged from 5\% to $50 \%$ with durational timeframes of simulation training ranging from 21 hours to two years (Bogossian et al., 2019). Aspects of cognitive, psychomotor, and affective learning (Kern et al., 2009) were measured in these simulation programs with no negative outcomes reported at any percentage of direct substitution (Bogossian et al., 2019). Similar results were found in a randomized controlled trial of clinical training for 325 SLP students in Australia (Hill, et al., 2020). Simulation experiences were substituted for $20 \%$ of clinical practice for 138 of those participants 
with no significant differences in competency-based outcomes compared to the control group $(n=150)$ who completed traditional clinical experiences. Hill and colleagues (2020) concluded that simulated experiences can partially replace clinical practice in speech-language pathology without compromising clinical competencies. In a second article, investigators provided a framework for how SLP academic programs can implement simulation into curricula (Hewat, et al., 2020). Along with recommendations from the Council of Academic Programs in Communication Sciences and Disorders (CAPCSD) simulation task force (2019), resources are available to help accredited academic programs navigate the $20 \%$ allowance for clinical contact hours in simulation established by ASHA's CFCC (2020).

\section{Simulation in Speech-Language Pathology}

Although simulation experiences in speech-language pathology are limited to 75 clinical contact hours, there is no limit on how much simulation can be implemented as an instructional tool. For years, faculty have been using basic simulation principles with case study discussions, data collection activities, or articulation and phonology exercises using mock speech samples. Dudding and Nottingham (2018) identified part-task trainers, computer-based simulations, manikins, and standardized patients as the four primary simulation learning modalities utilized in SLP education programs. For example, task training techniques in transnasal endoscopy were found to be effective with a range of low to high fidelity simulation materials (Benadom \& Potter, 2011; Berkowitz, 2017). Computer-based simulations outperformed didactic instruction on learning outcomes in a child language disorders course (Carter, 2019). Use of manikins for training in dysphagia competencies contributed to successful performance assessments and positive student perceptions of their knowledge, confidence, and preparedness for clinical services (Miles et al., 2016). Finally, learning experiences with simulated patients (i.e., actors portraying a simulation role) or standardized patients (i.e., patients repeatedly presenting their case for uniform learner experiences) has accounted for much of speech-language pathology's history in simulations. For example, standardized patients and simulated patient experiences have been utilized for clinical skills related to stuttering (Lohman, 2008), aphasia (Zraick et al., 2003), augmentative and alternative communication (Howells et al., 2019), infant feeding (Ferguson \& Estis, 2018), and management of difficult client behaviors (Bressmann \& Eriks-Brophy, 2012).

Each simulation method can be effective when paired with learner-centered experiences that include skillful instruction, considered practice, and realism (Kneebone, 2005). Realism is referred to as fidelity in the simulation domain. Fidelity reflects the replicated accuracy of the simulation participants, equipment, and environment (i.e., event surroundings) and is often rated as low, medium, or high (Seropian et al., 2004b). The realism component is most evident in simulated hospital environments when participants are well prepared, medical equipment is operational, dynamic manikins have a lifelike appearance with interactive voice and biometrics (e.g., heartrate, blood pressure, breath sounds), and the space is designed with setting expected accessories. These high fidelity, acute care simulation components are foundational to training in many healthcare professions.

The acute care scope of practice in speech-language pathology challenges many novice clinicians when patients with complex medical needs require services in the intricate physical and technical environment of an acute care setting. This clinical challenge aligns well with the patient safety 
mission of simulated learning environments where training can prevent mistakes in clinical decision-making or procedural skills that have critical consequences (Ziv et al., 2000). Evidence from a systematic review of nursing literature suggested that high fidelity simulation training increased learner confidence, while also reducing anxiety when faced with the awareness of those consequences (Labrague et al., 2019). Investing in the development of acute care simulations in SLP could maximize the educational value of advanced cognitive (i.e., knowledge) and psychomotor (i.e., skills) components of learning plus heighten the essential affective (i.e., emotional) aspect, as well.

Several clinical training paradigms in acute care SLP skills have been successful when implemented in a high-fidelity simulated learning environment. Speech-language pathologists with minimal prior experience in tracheostomy management skills significantly increased in clinical competency and confidence after a one-day training course that utilized both part-task trainers and high fidelity, manikin-based live simulations (Ward et al., 2014). Opportunity was created for those novice clinicians to apply curricular knowledge without compromising patient safety. Collaborative care for patients with dysphagia between nursing and SLP students was also effectively simulated in a high-fidelity nursing lab environment using a manikin with biometric capabilities (Grillo \& Thomas, 2016). Potter and Allen (2013), however, suggested that manikin fidelity was not essential to quality learning experiences when strong curricular instruction of SLP students was paired with active learning using low-fidelity, static manikins in the high-fidelity environment of a nursing simulation lab. Unfortunately, achievement of environmental and physical (i.e., manikin) fidelity is often expensive and therefore, cost prohibitive. While these examples demonstrate the value of collaborative educational experiences and shared resources with our interprofessional colleagues in nursing, limitations remain in the access to those highfidelity spaces.

Expense is the primary deterrent to more accessible and programmatic incorporation of simulation into graduate education in speech-language pathology. Programs are often charged with finding unique ways to provide innovative learning opportunities despite limited faculty, space, and financial resources. A study by Dudding and Nottingham (2018) explored the barriers to the implementation and expansion of simulated learning experiences in communication science and disorders (CSD) programs. While the authors identified a variety of barriers, including time constraints and knowledge of available simulation technology, the authors cited cost and availability of simulation facilities as the top two barriers to nonusers of simulations. Although inexpensive task trainers and computer-based simulations are effective and available, development of a simulation program for graduate instruction with equipment and infrastructure that add immersive fidelity to learning experiences is appealing.

\section{Simulation Program Development}

Academic programs in speech-language pathology that want to build a simulation program must address the fidelity of simulation infrastructure, as well as the quality of curriculum design, implementation, and evaluation. Fortunately, a discipline-specific document to identify best practices in simulations was published (CAPCSD, 2019). This white paper provided guidance for implementing simulations into clinical curricula with evidence-based knowledge from both within and outside the field of speech-language pathology. This document, along with other seminal 
works from Jeffries (2005), the Medical Council of Canada (2013), the International Nursing Association for Clinical Simulation and Learning (2016), and the Accreditation Council for Graduate Medical Education (2020) are foundational to understanding the design and implementation of quality simulation experiences. In addition, practical recommendations to clinical educators for starting a simulation program in a sequenced plan of component steps including vision, business plan, buy-in, facility construction, equipment purchases, training, curriculum development, faculty development, infrastructure, and policies were provided by Seropian and colleagues (2004a).

The development of the simulation lab and acute care simulation practicum course presented in this paper was designed using resources cited above and counsel from interprofessional colleagues in nursing, nutrition, and theater programs. The ten-month timeline of the plan was adapted from the recommendations by Seropian et al (2004a) and categorized into four phases: 1) administrative preparation, 2) lab construction, 3) curriculum development, and 4) implementation. See Figure 1 for the timeline. The components of these four phases as they apply to development of a dedicated, acute care simulation program in speech-language pathology are described below.

\section{Figure 1}

Timeline for Development of the Simulation Program

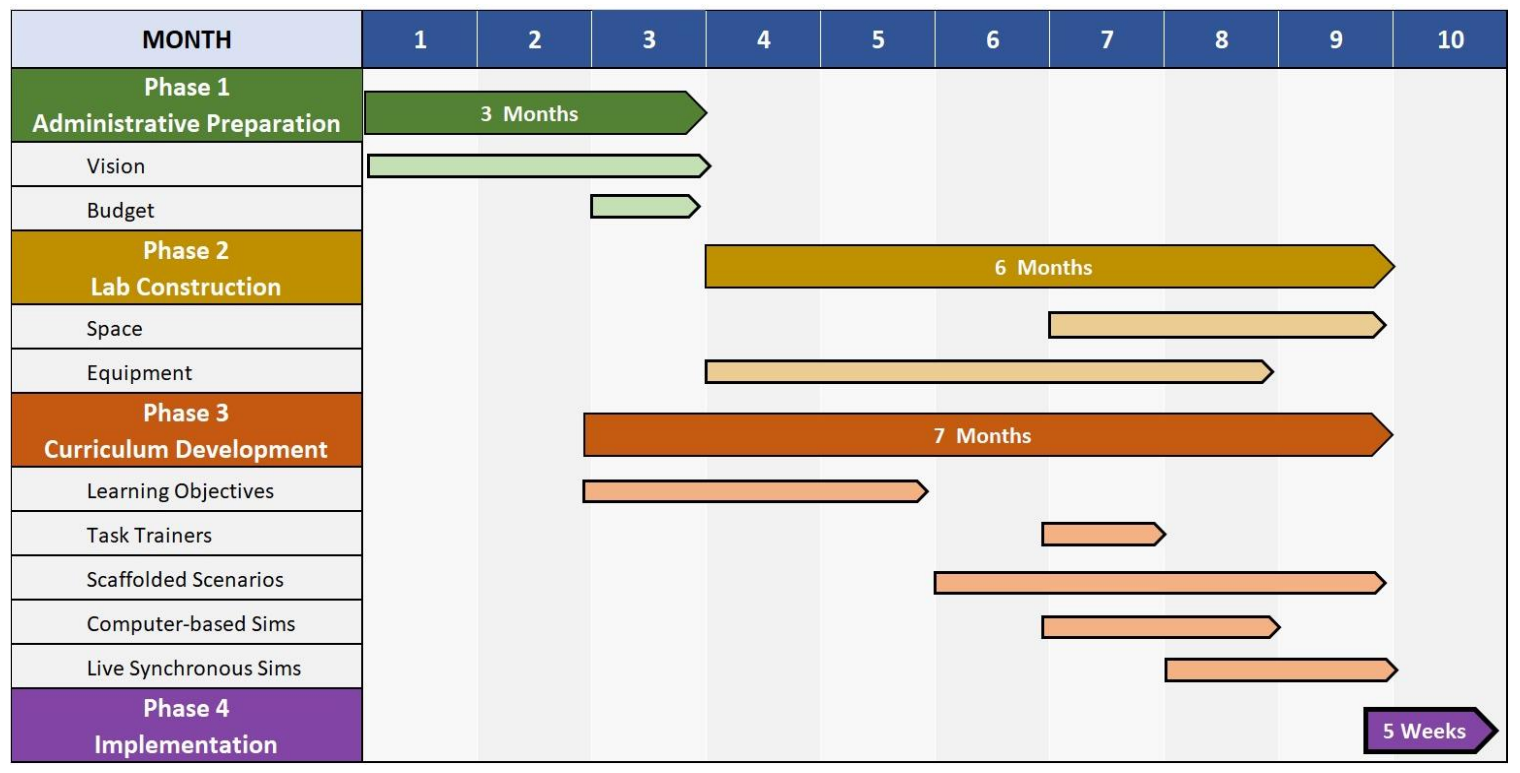

\section{Phase 1 - Administrative Preparation}

\section{Vision}

The faculty vision for this simulation program was to provide increased opportunity to develop and apply acute care clinical skills in a simulation lab dedicated to SLP students. The focus was derived from logistical and experiential challenges to clinical training identified by the faculty upon review of caseloads within the university clinic and systematic program review. First, 
outpatient campus clinics do not offer many opportunities to apply acute care skills. Nursing simulation labs are excellent resources but can be confounded by shared scheduling and governance issues. Second, clinical clock hour accrual is often delayed or reduced in acute care internships due to patient safety issues and gradual student assimilation for skill and confidence development. These factors contributed to the prioritized pursuit of acute care simulation experiences for students over other possible simulation applications.

\section{Budget}

An internal infrastructure grant competition was the impetus to accelerate plans for this simulation program. The authors are members of an interprofessional teaching circle with faculty from nursing, nutrition, and theater programs. Collaboration on the grant led to shared resources to create discipline specific simulation spaces. After dividing the $\$ 25,000$ grant, speech-language pathology was allocated $\$ 8,900$ for infrastructure purchases. While budgeting often begins with a calculation of need, this budget was determined more by fair distribution of a shared resource.

The challenge of building a simulation lab with $\$ 8,900$ was approached with two options: 1 ) invest funds in one piece of high-fidelity equipment and build the program gradually, or 2) create a costeffective alternative to physical and environmental fidelity. Simulation labs with operational medical equipment and multiple, high-fidelity manikins range in cost from $\$ 150,000$ to $\$ 750,000$ and are cost prohibitive in most SLP programs. Therefore, these authors approached outfitting the simulation lab with the understanding that simulations are "a technique - not a technology" and that the goal is to provide "guided experiences that evoke or replicate substantial aspects of the real world in a fully interactive manner" (Gaba, 2004, p. i2). As such, the faculty chose the second option and pursued cost-effective alternatives to medical equipment and materials that could replicate the hospital environment with as much fidelity as affordable.

\section{Phase 2 - Lab Construction}

\section{Space}

Before purchasing medical equipment for the simulation lab, space planning needed to address logistical issues of access, security, and capacity. For students and faculty to access the full capabilities of instructional technology in the simulation lab, the room needed to be within range of a video recording system for the campus clinic. Storage for simulation equipment also needed to be accessible. Although the simulation lab was outfitted with low-cost alternatives to high fidelity simulation materials, the security of those items required an entrance that could be locked and monitored by clinic staff. Finally, the capacity of the room had to be large enough to support hospital room furnishings, graduate students, a facilitator, and a standardized patient. This simulation lab replaced a 150 square foot computer lab and was developed to seat eight adults comfortably. However, if a real hospital bed and larger control center furnishings were included, that capacity would not be functional which highlights the need for thoughtful attention to the dimensions of equipment and space, as well as function prior to purchases. See Figure 2 for photos of the simulation lab infrastructure. 
Figure 2

Simulation Lab Infrastructure

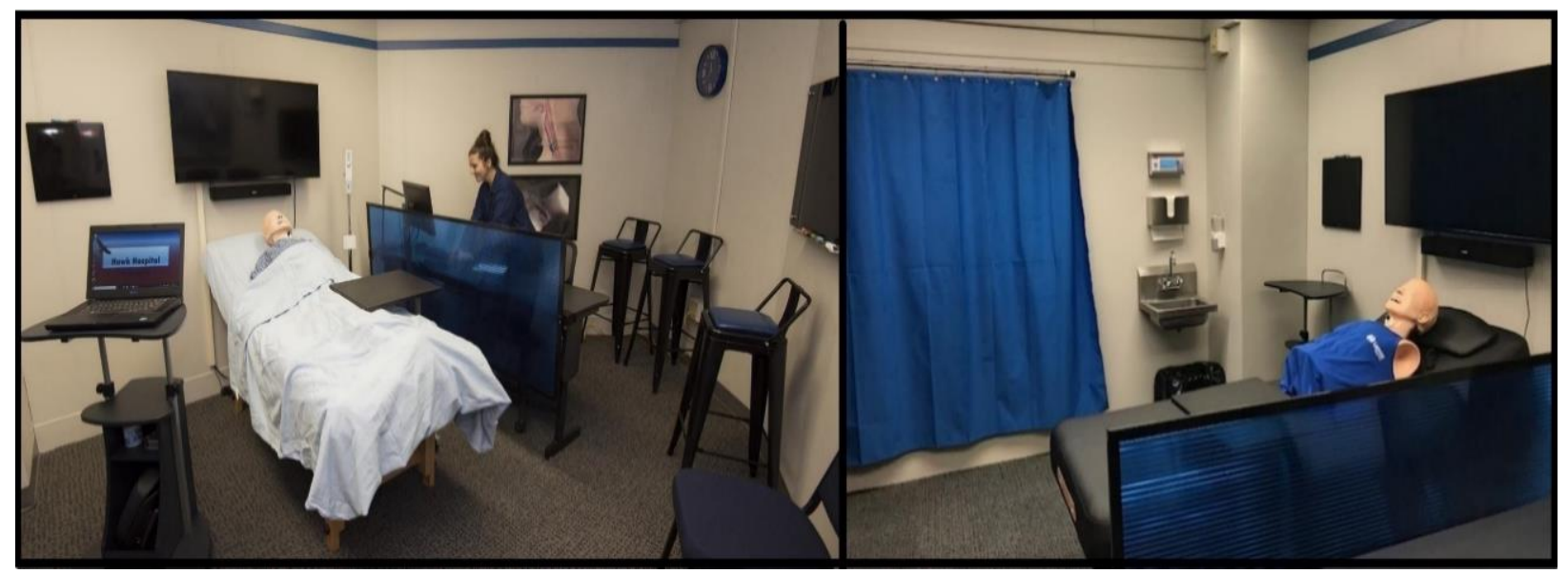

\section{Equipment}

Cost-effective alternatives, that save both space and expense when compared to standard equipment in an acute care setting, can be found outside of medical catalogs. For example, this simulation lab was outfitted with an adjustable massage table instead of an electric hospital bed for thousands in savings and a much smaller footprint. A stretcher would also be a functional alternative but at a higher cost than the massage table. A \$23 application, SimMon (Castle Anderson Aps, 2010), on a tablet simulates a bedside health monitor with linked access for facilitator manipulation of vital signs associated with aspiration or hypoxia. A standing laptop cart is a simple substitution for a cart-on-wheels used for point of service documentation. A large computer monitor behind the bed converts the hospital room into a radiology suite with modified barium swallow video clips played by the facilitator during simulation scenarios. The monitor can also be used to display endoscopic swallowing evaluations. Students can simulate these exams by using a \$20 scope designed for car engine diagnostics that fits perfectly through the nostril of a manikin. Furthermore, there is no need for a manikin with arms and legs, as a half-torso, low fidelity version with an upper aerodigestive tract and tracheostomy, NG Tube and Trach Care Trainer (Laerdal Medical, 2015), serves the SLP service delivery needs and saves thousands of dollars. The control station for the facilitator who is manipulating the technology of the simulation can be just as effective with visual rather than physical separation as found in a typical control room. Similar cost-saving substitutions were made throughout the lab bringing the grand total down to $\$ 8,900$. See Table 1 for expense comparisons. See Figure 3 for a photo comparison of this lab to a high-fidelity nursing lab on campus. Selection of these cost-saving equipment substitutions were tailored to the emerging curriculum which was being developed simultaneously. 


\section{Table 1}

Simulation Equipment Expenses

\begin{tabular}{|c|c|c|}
\hline Simulation Equipment Expenses & $\begin{array}{c}\text { High Fidelity } \\
\sim \text { Cost }\end{array}$ & $\begin{array}{c}\text { Low Fidelity } \\
\sim \text { Cost }\end{array}$ \\
\hline Manikin with Tracheostomy and Accessories & $\$ 80,000$ & $\$ 2,000$ \\
\hline Video Recording System & $\$ 5,000$ & $\$ 2,000$ \\
\hline Simulated Health Monitor & $\$ 6,000$ & $\$ 1,800$ \\
\hline Audio Visual Equipment & $\$ 5,500$ & $\$ 1,100$ \\
\hline Supervisor Control Station & $\$ 5,000$ & $\$ 650$ \\
\hline Hospital Bed and Bedside Table & $\$ 15,000$ & $\$ 500$ \\
\hline Observation Area Seating & $\$ 500$ & $\$ 350$ \\
\hline Patient Precautions (privacy curtain, sink, protective equipment) & $\$ 600$ & $\$ 250$ \\
\hline Linens (hospital gowns, bedding, lab coats) & $\$ 300$ & $\$ 150$ \\
\hline Cart-on-Wheels for Documentation & $\$ 1,000$ & $\$ 100$ \\
\hline Labor for Construction & $\$ 10,000$ & $\$ 0$ \\
\hline Total & $\$ 128,900$ & $\$ 8,900$ \\
\hline
\end{tabular}

\section{Figure 3}

High Fidelity vs. Low Fidelity Equipped Lab

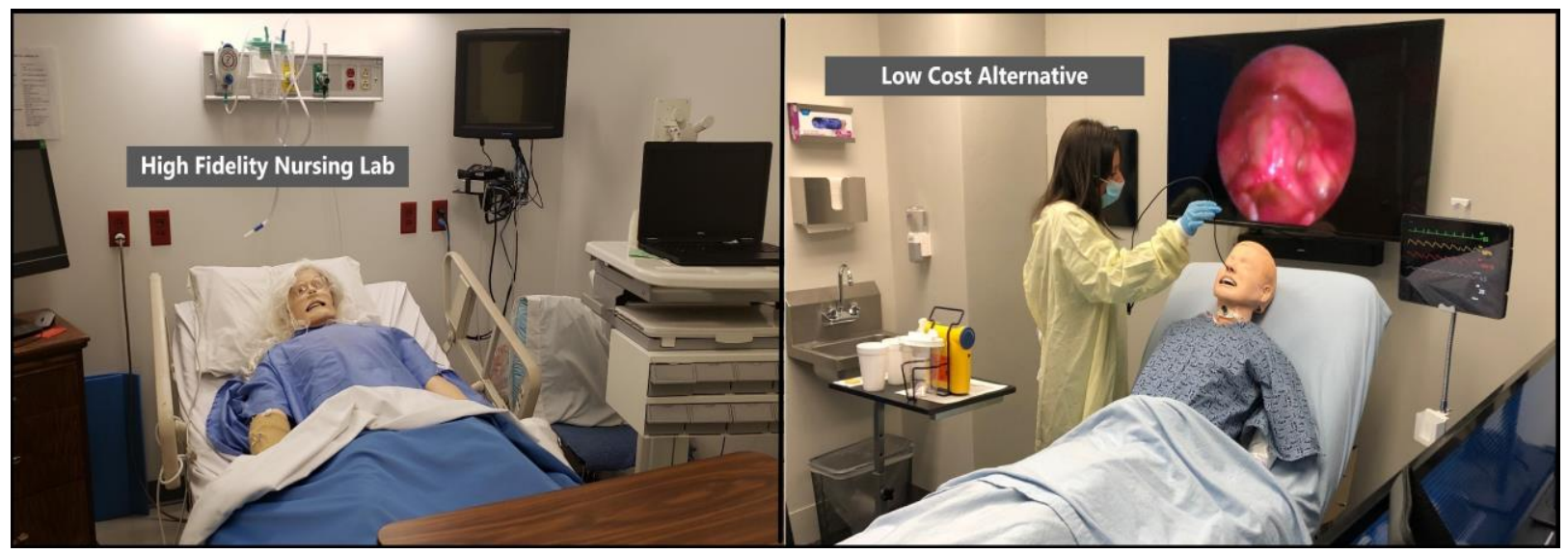

\section{Phase 3 - Curriculum Development}

\section{Learning Objectives}

Development of the acute care simulation practicum course was guided by the work of the CAPCSD Task Force's work on Best Practices in Healthcare Simulations (2019) and Kern's work on the steps of curriculum development (Thomas et al., 2016). In keeping with Step 1 of Kern's six steps in curriculum development, the faculty identified an educational gap with respect to application of the knowledge for dysphagia assessment, intervention, and management from 
review of acute care internship supervisor comments on second-year graduate student midterm evaluations. Similarly, the faculty identified two barriers in obtaining more practical, hands-on experiences: limitations in the type and medical complexity of the dysphagia needs of clients receiving services in the campus clinic, and the demands of a graduate curriculum sequence in which the bulk of didactic coursework is condensed into three semesters prior to completion of two, full-time internship experiences. As such, curriculum revisions were made that prioritized simulation-based learning opportunities over didactic instruction time through a piloted, one credit, acute care practicum course.

The curriculum revisions shifted learning objectives and one credit from a didactic course in diagnostic methods to this practicum course with similar, but specified content. The identification of learner objectives for the practicum course and scenario development were closely intertwined and focused on scaffolding student learning in the simulated environment. Learner objectives were specific to each case scenario and spanned the three domains of learning: cognitive, psychomotor, and affective (Kern et al., 2009), while also incorporating the applicable knowledge and skills from standards IV and V of ASHA's Standards and Implementation Procedures for the Certificate of Clinical Competence (CCC) in Speech-Language Pathology (2020). Although the 2014 standards were originally referenced, the updated 2020 standards are also applicable.

\section{Course Design}

Deliberate scaffolding was structured into the sequence of course content. The practicum course began with task trainers for basic workflow skills that were integrated into each subsequent live simulation. Then, scaffolded scenarios were introduced in asynchronous, computer-based simulations that incorporated multiple-choice clinical decision-making opportunities. The computer-based simulations were paired with synchronous live simulations and incorporated progressively more advanced clinical skills. The course culminated in a one-on-one, standardized patient assessment. See Figure 4 for a schemata of the scaffolding within the practicum course. Descriptions of each simulation component follow.

\section{Figure 4}

\section{Scaffolding of the Practicum Course}

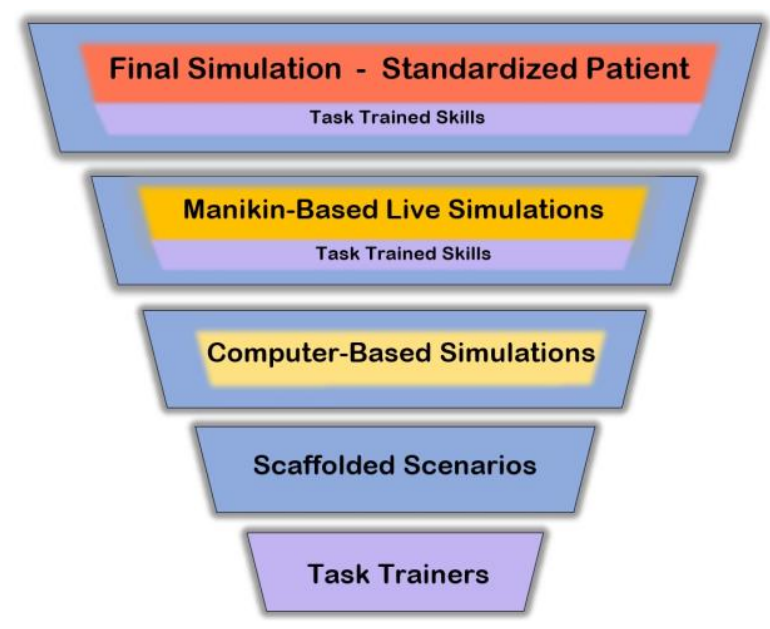


Task Trainers. The first aspect of course development was to identify activities that are a part of the daily workflow for speech-language pathologists in acute care settings. The students were initially engaged in workflow activities using a task-training approach, as task trainers have been touted as essential to the development of procedural clinical skills (Malekzadeh, 2017). These task training activities included review of orders, hand hygiene, and donning and doffing personal protective equipment, to name a few. Workflow task trainers were then structured into each synchronous, live simulation experience in an effort to increase the graduate students' automaticity of these skills.

Scaffolded Scenarios. The second aspect in which this simulation-based practicum experience was structured to scaffold learning was the creation of a series of case studies that focused on a limited number of patient profiles that evolved throughout the patient care experience. For example, over multiple clinics, the students followed a patient post-tracheotomy secondary to respiratory failure through completion of a speaking valve assessment, a cranial nerve focused oral mechanism examination and clinical swallow evaluation, as well as a modified barium swallow study. See Figure 5 for photos. The purpose of these carefully designed, repeat case profiles was for students to assess changes in patient condition, critically evaluate possible explanations for those changes, and determine the clinical implications that the changes had on the diagnosis, recommendations, and anticipated outcomes. Again, the purpose of these repeated case profiles was to support students' critical thinking through conceptual continuity. An example case history and simulation outline for the initial and scaffolded scenario, as well as the corresponding learning objectives for each simulation are available in Appendix A.

\section{Figure 5}

\section{Speaking Valve and Modified Barium Swallow Scenarios}

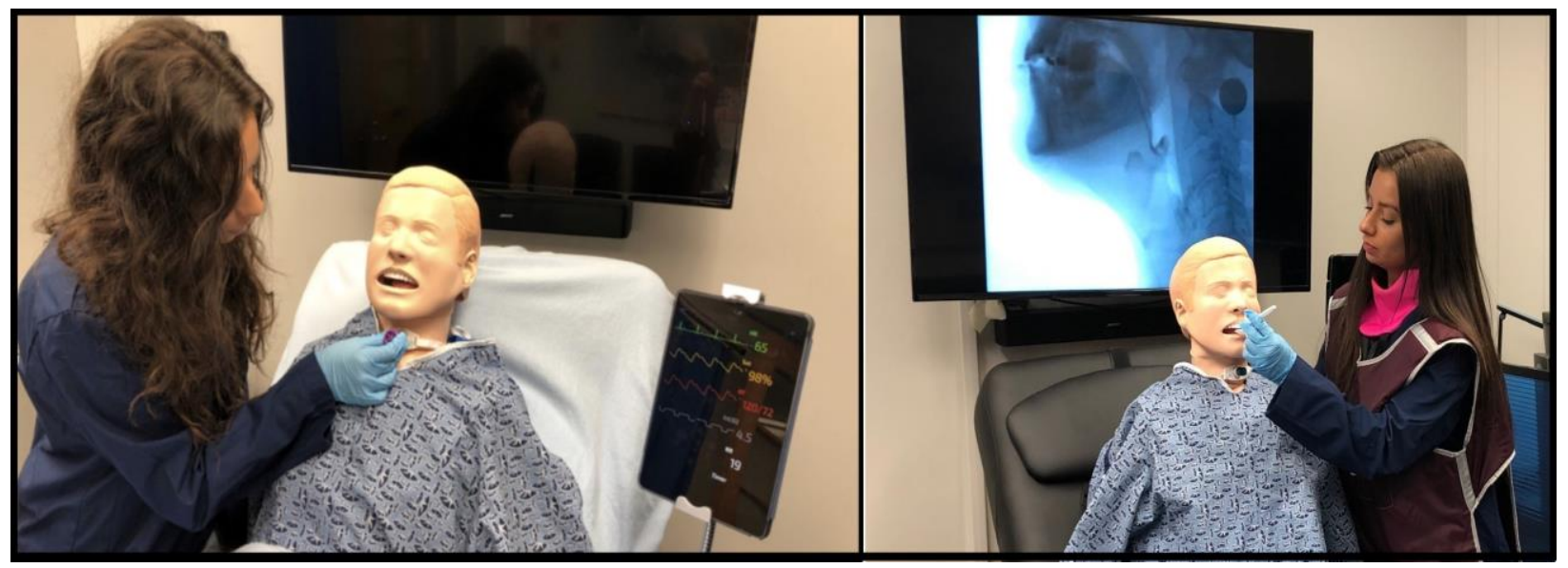

Asynchronous, Computer-Based Simulations. The next component of scaffolding was the development of asynchronous, computer-based simulations. Referred to by some in the literature as computer-based learning environments (CBLE), the preparatory use of computerbased simulations prior to live simulations is supported by Curtin and colleagues (2011). The aforementioned authors found that this simulation sequence improved achievement of learning 
goals and outcomes in pharmacology students and was even considered to improve participant confidence during the live simulations (Curtin, et al., 2011). The individualized student learning that is implicit to computer-based simulations has also been shown to improve live simulation experiences when sequenced (Donovan et al., 2018). Lastly, as acknowledged in the CAPCSD white paper entitled Best Practices in Healthcare Simulations: Communication Sciences and Disorders, computer-based simulations "are essential in the training of skilled clinicians with critical thinking abilities" (2019, p. 10). Consequently, the focus of these asynchronous activities was clinical decision-making rather than fidelity.

During this pilot practicum, low fidelity, computer-based simulations utilizing PowerPoint (Microsoft, 2016) were constructed and assigned to the students to review prior to completion of the live simulation activities. Using the action feature available in PowerPoint, 'buttons' were created that allowed the students to direct the course of the assessment or intervention through individualized selections. As students proceeded through the asynchronous simulation, additional information was provided that the student needed to integrate in order to determine the next course of action and ultimately, to diagnose, make recommendations, and develop a plan of intervention. As acknowledged by Van der Kleij and colleagues (2015), feedback is a critical component of computer-based learning. The feedback that was structured into the low-fidelity, computer-based simulations was multidimensional to support critical thinking pathways during the asynchronous learning opportunity. Moreover, the feedback provided opportunities for discussion during the debriefing. The feedback included knowledge of results, that is, whether the response was correct, partially correct, or incorrect without providing the correct response; elaborated feedback in the form of additional information for both correct and incorrect responses; and the opportunity to attempt the question again in light of the elaborated feedback (Shute, 2008). See Table 2 for examples of feedback embedded within the computer-based, PowerPoint simulations.

\section{Table 2}

Examples of Feedback by Type

\begin{tabular}{|c|c|}
\hline Type of Feedback & Example Feedback from the Computer-Based Simulation \\
\hline \multirow{3}{*}{ Knowledge of Results } & $\begin{array}{l}\text { That's correct! The patient's history of Parkinson's Disease, as well as recent } \\
\text { intubation/extubation have possible implications for a history of dysphagia or current } \\
\text { cause/exacerbation of dysphagia symptoms, respectively. Continue. }\end{array}$ \\
\hline & $\begin{array}{l}\text { That is partially correct. Being awake and alert are conditions required for completing a } \\
\text { speaking valve assessment. However, additional factors must also be considered. Try again. }\end{array}$ \\
\hline & $\begin{array}{l}\text { That is incorrect. The patient's past medical history is significant for cardiac disease. As a } \\
\text { result, although the patient has pharyngeal residues, techniques requiring the patient to bear } \\
\text { down, such as the effortful swallow, are contraindicated. Try again. }\end{array}$ \\
\hline Elaborated Feedback & $\begin{array}{l}\text { That is correct! The patient presents with asymmetrical deficits. As a result, the patient } \\
\text { should be trialed in the A-P view with a head turn to the weak (right) side. If effective in } \\
\text { reducing pharyngeal residues, the patient should be trialed with this compensatory } \\
\text { position in the lateral view to determine the effect on airway protection. Continue }\end{array}$ \\
\hline $\begin{array}{l}\text { Opportunity to Attempt } \\
\text { the Question Again }\end{array}$ & $\begin{array}{l}\text { That is partially correct. While a tracheostomy is associated with disorders of abductor and } \\
\text { adductor laryngeal reflexes, desensitization of the oropharynx and larynx, reduced subglottic air } \\
\text { pressure, and diffuse atrophy of the laryngeal muscles, all of which increase the patient's risk of } \\
\text { aspiration, the presence of a tracheostomy is only one piece of the patient's current medical } \\
\text { course that increases the patient's risk of dysphagia. Try again. }\end{array}$ \\
\hline
\end{tabular}


Debriefing. Prior to completion of the live simulation, the students participated in a debriefing of the asynchronous scenario. Per the recommendation of Fanning and Gaba, the debriefing was tailored to the specific learning objectives identified at the beginning of each asynchronous simulation (2007). The duration of the debriefings was fluid, but at a minimum, met the $25 \%$ supervision requirement as specified by ASHA's certification standards for asynchronous simulation (CFCC, 2020). Debriefing, as well as participation in the live simulation experiences were prefaced by the establishment of the expectation of confidentiality, as well as the establishment of a mentally, emotionally, and intellectually safe environment that was both collaborative and geared toward learning through shared exploration (Gardner, 2013). Consistent with the recommendations of Grillo and Thomas, the SLP faculty facilitator observed debriefings led by nursing faculty prior to the pilot, consulted the literature regarding debriefing, and utilized debriefing resources provided by nursing colleagues to structure the debriefing sessions (2016). Following review of debriefing literature, the authors initially adopted the three-phased gather, analyze, summarize (GAS) model (Sawyer et al., 2016) as it most closely mirrored the model students experienced during interprofessional simulations with nursing and nutrition programs and contained elements evident in multiple other frameworks. In keeping with the GAS model, the debriefing session began with a review of the simulation's case history to gather essential information and establish a "shared mental model" (p. 212). Next, the analyze portion of the debriefing for both the asynchronous and synchronous simulations was guided by open-ended questions geared toward reflection of thought processes regarding the cognitive, psychomotor, and affective aspects of the simulation. Debriefing questions focusing on the cognitive aspect of clinical decision-making during the simulation included discussion of the patient's clinical presentation, observations regarding changes in the patient's status, and knowledge of related diagnoses, to name a few. Open-ended questions regarding the psychomotor aspects of the simulation focused on areas such as the effectiveness of the patient interview, review of the administration of the assessment, and evaluation of the effectiveness of the Situation, Background, Assessment, Recommendation (SBAR) communication framework used to interact with the mock team members (Shahid \& Thomas, 2018). Debriefing of the affective aspects included a guided, self-reflection of confidence related to the cognitive and psychomotor aspects of the simulation. The final phase was an opportunity to review and summarize the simulation objectives. The authors employed the advocacy-inquiry strategy of the "debriefing with good judgement" framework (Rudolph et al., 2007, p. 362) from which clinical decision making was fostered through exploration of the students' frames or assumptions and guided self-reflection of the results of the simulation. The simulation closed with a discussion of lessons learned.

Synchronous, Live Simulations. The final aspect of the scaffolded learning experience involved the integration of asynchronous, computer-based simulations with synchronous, live simulation experiences involving either manikins or simulated patients. The debriefing of the asynchronous simulation served as a prebrief to the synchronous simulation experience. Students were drawn at random to participate in the live simulations. Each live simulation was structured to last approximately 10 to 15 minutes and was immediately followed by a debriefing that mirrored that of the asynchronous debrief. Given the flexibility of the duration of the debrief for both the asynchronous and synchronous simulation experiences, any remaining time was utilized to complete additional iterations of the case scenario with minor changes to the findings to challenge the students' critical thinking and the corresponding debriefing. The course culminated with individualized completion of a synchronous simulation involving a standardized patient. During 
completion of this final simulation activity, students were challenged to integrate the various cognitive and psychomotor skills that they practiced or observed in isolation throughout the duration of the semester, to include but not limited to the following: ensuring patient safety and privacy; conducting a patient interview; administering an oral motor mechanism examination and clinical swallowing evaluation; analyzing observations to inform the diagnosis, recommendations, and referrals; and communicating effectively with the patient and mock nursing staff using established communication frameworks.

\section{Phase 4 - Implementation}

The acute care practicum course was added to the curriculum as a one credit "Special Topics" course for the pilot year. The course met two-and-a-half hours per week which was consistent with other clinical courses in the curriculum. As a pilot, the course was structured into different sections with one section completed simultaneous to the graduate-level swallowing disorders course during a typical 15-week semester, and two sections scheduled the semester following completion of the corresponding dysphagia coursework in an intensive five-week, block-format semester. Anecdotal evidence from student reports and faculty observations across the sections suggest that greater depth and breadth of synthesis of knowledge and critical thinking were observed in sections completing the simulation course after completion of the corresponding coursework. Student performance was ultimately assessed using a competency-based rating scale for the knowledge and skills exhibited throughout the duration of the semester, as well as in the students' final, individual simulation. These competencies were derived from the knowledge and skills from standards IV and V of ASHA's Standards and Implementation Procedures for the Certificate of Clinical Competence in Speech-Language Pathology (2020). The competency data is currently being reported at the university level as a measure of student learning outcomes for the graduate program in speech-language pathology. See Appendix B for the competency scale utilized for evaluation of student performance.

To date, student feedback regarding this course in skill and confidence preparation for healthcarerelated internships has been overwhelmingly positive. One student reported,

While completing my medical externship within an acute care setting, I found myself grateful for the simulation lab experience that IUP implemented. From preparing us for bedside swallowing evaluations to interpreting Modified Barium Swallow Study results, I was able to take all of the knowledge gained from our simulation lab and apply it during my acute care externship. This lab helped me gain hands-on clinical experience with medical terminology, patient care, and hospital protocol that I otherwise would not be able to obtain from simply reading from a textbook (M. John, personal communication, December 30, 2019).

Another stated,

Prior to the simulation clinic, I was apprehensive about my medical placement during my second year of graduate school; however, following the simulation clinic, I felt fully prepared to take on my placement in a rehabilitation hospital. I was frequently complimented by my supervisors at the hospital on my knowledge during our modified barium swallow studies, my confidence, and the rapport I built with patients, and I give all credit to our simulation clinic at IUP (B. Burfield, personal communication, December 31, 2019). 


\section{Lessons Learned}

\section{Equipment}

Simulated learning experiences offer an excellent platform to integrate culturally and linguistically diverse learning opportunities into clinical practica that might not otherwise be available due to the demographics of the geographic location. While the authors structured diversity elements into the case history information of each scenario, the fidelity of some of these elements was limited by the equipment. The low-cost, half-torso tracheostomy training manikin is only available with light skin. Other options in skin color and facial features are available with the purchase of more expensive, full-size manikins and may be worth the fidelity investment.

\section{Simulations}

Structuring the pilot simulation course into multiple sections yielded both advantages and disadvantages upon review. The inclusion of multiple course sections provided students with more opportunities for hands-on participation in the simulation experiences throughout the duration of the semester. However, simulated learning is inherently unpredictable and as such, there is the potential for different experiences and learning opportunities to naturally arise in one section but not another. Therefore, the faculty facilitator realized the need to introduce foils or other structured events to ensure that certain elements of the simulation were experienced consistently across the sections. For example, in one section, a student may be unable to remove the speaking valve from the universal hub of a dual-canula, tracheosotomy tube and as such would be challenged to troubleshoot and engage in clinical decision making while the manikin's oxygen saturation was rapidly declining. However, if students in subsequent sections easily remove the speaking valve during each attempt, they would not be afforded the same learning opportunities as students in the aforementioned section. While not every possible outcome can be anticipated, possible variations should be considered during the construction of each simulated case. Lastly, given that it is widely accepted that debriefing is the cornerstone of the simulation experience, the authors acknowledge that in addition to scenario refinement, the debriefing represents an area of ongoing development as the program moves from the pilot phase into an existing part of the curricular sequence.

\section{Student Performance}

Review of student learning outcomes reported at the university level aided in identification of areas that should be addressed earlier in the semester and/or should be more fully integrated into each simulation experience to provide more opportunities for practice and refinement. For example, the students would benefit from additional opportunities to implement patient and SBAR communication frameworks in order to gain increased comfort and proficiency. Similarly, given the scaffolded nature of the scenarios, simulations requiring the development of a plan of care and corresponding measurable goals are completed during the latter half of the semester. As such, students would benefit from increased and earlier opportunities to draft measurable, dysphagia management goals for a variety of patient profiles. 


\section{Conclusion}

The authors are hopeful that this article provides speech-language pathology programs a practical, cost-effective framework for structuring a dedicated simulation space and course, while empowering faculty to more fully integrate simulation-based learning experiences into their curricula in a way that is evidence-based and in keeping with the best practice resources that are currently available in the field of speech-language pathology.

\section{Disclosures}

The authors have no relevant financial or nonfinancial relationships to disclose.

\section{Acknowledgments}

The authors would like to thank the Deans of the Graduate School and the College of Education and Communications at Indiana University of Pennsylvania for their support in funding the development of the dedicated simulation lab. In addition, the authors would like to thank the Facilitating Student Learning Through Interprofessional Simulation teaching circle, of which the authors are active members, for its guidance and support of the integration of simulation in the speech-language pathology program.

\section{References}

Accreditation Council for Graduate Medical Education. (2020). The Milestones Guidebook. https://www.acgme.org/Portals/0/MilestonesGuidebook.pdf

American Speech-Language-Hearing Association. (2016). Standards for the Certificate of Clinical Competence in Speech-Language Pathology. https://www.asha.org/certification/certification-standards-for-slp--clinical-simulation/

American Speech-Language-Hearing Association. (2020). 2020 Standards and Implementation Procedures for the Certificate of Clinical Competence in Speech-Language Pathology.

Benadom, E.M. \& Potter, N.L. (2011). The use of simulation in training graduate students to perform transnasal endoscopy. Dysphagia, 26, 352-360.

Berkowitz, S.S. (2017). Teaching transnasal endoscopy to graduate students without a hospital or simulation laboratory: Pool noodles and cadavers. American Journal of Speech-Language Pathology, 26, 709-715.

Bogossian, F.E., Cant, R.P., Ballard, E.L., Cooper, S.J., Levett-Jones, T.L., McKenna, L.G., Ng, L.C., \& Seaton, P.C. (2019). Locating 'gold standard' evidence for simulation as a substitute for clinical practice in prelicensure health professional education. Journal of Clinical Nursing, 28(21-22), 3759-3775. 
Brannan, J., White, A., Bezanson, J. (2008). Simulator effects on cognitive skills and confidence levels. Journal of Nursing Education. 47 (11), 495-500.

Bressmann, T. \& Eriks-Brophy, A. (2012). Use of simulated patients for a student learning experience on managing difficult patient behaviour in speech-language pathology contexts. International Journal of Speech-Language Pathology, 14(2), 165-173.

Burns, H.K., O’Donnell J., Artman, J. (2010). High-fidelity simulation in teaching problemsolving to $1^{\text {st }}$-year nursing students. A novel use of the nursing process. Clinical Simulation in Nursing, 6, 87-95.

Carter, M.D. (2019). The effects of computer-based simulations on speech-language pathology student performance. Journal of Communication Disorders, 77, 44-55.

Castle Anderson Aps. (2010). SimMon (Version 1.8.6) [Mobile App]. App Store. https://apps.apple.com/us/app/simmon/id364731597

Cook, D. A., Hatala, R., Brydges, R., Szostek, J. H., Wang, A. T., Erwin, P. J., \& Hamstra, S. J. (2011). Technology-enhanced simulation for health professions education: A systematic review and meta-analysis. Journal of the American Medical Association. 306(9), 978-988.

Council of Academic Programs in Communication Sciences and Disorders. (2019). White paper: Best Practices in Healthcare Simulations: Communication Sciences and Disorders. https://wordpressstorageaccount.blob.core.windows.net/wp-media/wpcontent/uploads/sites/1023/2019/06/eBook-Best-Practices-in-CSD-March-2019.pdf

Council for Clinical Certification in Audiology and Speech-Language Pathology of the American Speech-Language-Hearing Association. (2014). Standards for the certificate of clinical competence in speech-language pathology. http://www.asha.org/Certification/2014Speech-Language-Pathology-CertificationStandards/

Curtin, L., Finn, L., Czosnowski Q, Whitman, C., \& Cawley, M. (2011). Computer-based simulation training to improve learning outcomes in mannequin-based simulation exercises. American Journal of Pharmaceutical Education, 75(6), Article 113.

Donovan, L., Argenbright, C., Mullen, L., \& Humbert, J. (2018). Computer-based simulation: Effective tool or hinderance for undergraduate nursing students? Nurse Education Today, 69, 122-127.

Dudding, C., Nottingham, E. (2018). A National Survey of Simulation Use in University Programs in Communication Sciences and Disorders. American Journal of Speech-Language Pathology, 27, 71-81. https://pubs.asha.org/doi/pdf/10.1044/2017_AJSLP-17-0015

Eliadis, M. \& Verkuyl, M. (2019). Balancing the budget in the simulation centre. Clinical Simulation in Nursing, 37C, 14-17.

Fanning, R., Gaba, D. (2007). The role of debriefing of simulation-based learning. Simulation in Healthcare.2(2),115-125 https://journals.1ww.com/simulationinhealthcare/Fulltext/2007/00220/The_Role_of_Debr iefing in_Simulation_Based.7.aspx

Ferguson, N.F. \& Estis, J.M. (2018). Training students to evaluate preterm infant feeding safety using a video-recorded patient simulation approach. American Journal of SpeechLanguage Pathology, 27, 566-573.

Gaba, D.M. (2004). The future vision of simulation in health care. BMJ Quality \& Safety in Health Care, 13, i2-i10.

Gardner, R. (2013). Introduction to debriefing. Seminar in Perinatology, 37, 166-174. Inc. All rights reserved. 
Grillo, E.U. \& Thomas, C.M. (2016). Using high-fidelity simulation to facilitate graduate student clinical learning. Perspectives of the ASHA Special Interest Groups - SIG10, 1(1), 4-15.

Gonczi, A. (2013). Competency-Based Approaches: Linking theory and practice in professional education with particular reference to health education. Educational Philosophy and Theory, 45(12), 1290-1306.

Hayden, J. K. Smiley, R. A, Alexander, M., Kardong-Edgren, S., \& Jefferies, P. R. (2014). The NCSBN national simulation study: A longitudinal, randomized, controlled study replacing clinical hours with simulation in prelicensure nursing education. Journal of Regulation, 5(2), S3-S69.

Hewat, S., Penman, A., Davidson, B., Baldac, S., Howells, S., Walters, J., Purcell, A., Cardell, E., McCabe, P., Caird, E., Ward, E., \& Hill, A.E. (2020). A framework to support the development of quality simulation-based learning programmes in speech-language pathology. International Journal of Language \& Communication Disorders, 55(2), 287300.

Hill, A.E., Ward, E., Heard, R., McAllister, S., McCabe, P. Penman, A., Caird, E., Aldridge, D., Baldac, S., Cardell, E., Davenport, R., Davidson, B., Hewat, S., Howells, S., Purcell, A., \& Walters, J. (2020). Simulation can replace part of speech-language pathology placement time: A randomised controlled trial. International Journal of SpeechLanguage Pathology, Feb. 24, 2020, https://doiorg.proxyiup.klnpa.org/10.1080/17549507.2020.1722238

Holzman, R.S., Cooper, J.B., Gaba, D.M., Philip, J.H., Small, S.D., Feinstein, D. (1995). Anesthesia crisis resource management: Real-life simulation training in operating room crises. Journal of Clinical Anesthesia. 7(8), 675-687.

Howells, S., Cardell, E.A., Waite, M.C., Bialocerkowski, A., \& Tuttle, N. (2019). A simulationbased learning experience in augmentative and alternative communication using telepractice: speech pathology students' confidence and perceptions. Advances in Simulation, 4(Suppl 1), 23.

International Nursing Association for Clinical Simulation and Learning Standards Committee (2016, December). INACSL standards of best practice: Simulation design. Clinical Simulation in Nursing, 12(S), S5-S12. http://dx.doi.org/10.1016/j.ecns.2016.09.005

Issenberg, S.B., McGaghie, W.C., Petrusa, E.R., Gordon, D.L., \& Scalese, R.J. (2005). Features and uses of high-fidelity medical simulation that lead to effective learning: a BEME systematic review. Medical Teacher, 27(1), 10-28.

Issenberg, S.B. \& Scalese, R.J. (2008). Simulation in healthcare education. Perspectives in Biology and Medicine, 51(1), 31-46.

Jeffries, P.R. (2005). A framework for designing, implementing, and evaluating simulations used as teaching strategies in nursing. Nursing Education Perspectives, 26(2), 96-103.

Kern, D.E., Thomas, P.A., \& Hughes, M.T. (Eds.). (2009). Curriculum development for medical education: A six step approach. ( $\left.2^{\text {nd }} \mathrm{ed}\right)$. Johns Hopkins University Press.

Kneebone, R. (2005). Best practices in summative assessment. Advances in Physiology Education, 41(1), 110-119.

Labrague, L.J., McEnroe-Petitte, D.M., Bowling, A.M., Nwafor, C.E., \& Tsaras, K. (2019). High fidelity simulation and nursing students' perceptions of confidence and anxiety. A systematic review. Nursing Forum, 54 (3), 358-368.

Laerdal Medical. (2015). NG Tube and Trach Trainer. https://www.laerdal.com/us/doc/96/NGTube-and-Trach-Care-Trainer 
Lapkin, S., Levett-Jones, T., Bellchambers, H., Fernandez, R. (2010). Effectiveness of patient simulation manikins in teaching clinical reasoning skills to undergraduate nursing students: a systematic review. Clinical Simulation in Nursing, 6, 207-222.

Lohman, P. (2008) Students' perceptions of face-to-face pseudostuttering experience. Perceptual and Motor Skills, 107, 951-962.

Lopreiato, J. O. (Ed.), Downing, D., Gammon, W., Lioce, L., Sittner, B., Slot, V., Spain, A. E. (Associate Eds.), and the Terminology \& Concepts Working Group. (2016). Healthcare Simulation Dictionary. http://www.ssih.org/dictionary

Malekzadeh, S. (2017). Simulation in otolaryngology. Philadelphia, PA: Elsevier.

Maloney, S. \& Haines, T. (2016). Issues of cost-benefit and cost-effectiveness for simulation in health professions education. Advances in Simulation, 1. https://doi.org/10.1186/s41077016-0020-3

Medical Council of Canada. (2013). Guidelines for the Development of Objective Structured Clinical Examination Cases. https://mcc.ca/media/OSCE-Booklet-2014.pdf

Microsoft Corporation. (2020). Microsoft 365 Apps for Enterprise-PowerPoint. (Version 2007). [Computer Software]. https://www.microsoft.com/en-us/microsoft-365/powerpoint

Miles, A., Friary, P., Jackson, B., Sekula, J., \& Braakhuis, A. (2016). Simulation-Based Dysphagia Training: Teaching interprofessional clinical reasoning in a hospital environment. Dysphagia, 31, 407-415.

Potter, N.L. \& Allen, M. (2013). Clinical swallow exam for dysphagia: A speech pathology and nursing simulation experience. Clinical Simulation in Nursing, 9, e461-e464.

Rothgeb, M. (2008). Creating a nursing simulation laboratory: A literature review. Journal of Nursing Education. 47(11), 489-494.

Rudolph, J.W., Simon, R., Rivard, P., Dufresne, R., \& Raemer, D. (2007). Debriefing with good judgement: Combining rigorous feedback with genuine Inquiry. Anesthesiology Clinics. 25, 361-376. https://doi.org/10.1016/j.anclin.2007.03.007

Sanko, J. (2016). Healthcare simulation: A multi-billion-dollar solution to safter healthcare. Chief Information Officer Review Magazine. http://simulation.cioreview.com/cxoinsight/healthcare- simulationa-multibillion-dollarsolution-to-safer-healthcare-nid-15160-cid-136.html

Sanko, J. (2017). Simulation as a teaching technology. A brief history of its use in nursing education. The Quarterly Review of Distance Education, 18(2), 77-85.

Sawyer, T., Eppich, W., Brett-Fleegler, M., Grant, V., Cheng, A. (2016). More than one way to debrief: A critical review of healthcare simulation debriefing methods. Simulation in Healthcare: The Journal of the Society for Simulation in Healthcare. 11(3). 209-217. https://doi.org/10.1097/SIH.0000000000000148

Seropian, M.A., Brown, K., Gavilanes, J.S., \& Driggers, B. (2004a). An approach to simulation program development. Journal of Nursing Education, 43(4), 170-174.

Seropian, M.A., Brown, K., Gavilanes, J.S., \& Driggers, B. (2004b). Simulation: Not just a manikin. Journal of Nursing Education, 43(4), 164-169.

Seybert, A. (2011). Patient simulation in pharmacy education. American Journal of Pharmeceutical Education, 75(9), 187. https://doi.org/10.5688/ajpe759187

Shahid, S., Thomas, S. (2018). Situation, Background, Assessment, Recommendation (SBAR) communication tool for handoff in health care - A narrative review. Safety in Health. 4(7). 1-9. https://doi.org/10.1186/s40886-018-0073-1 
Shute, V. J. (2008). Focus on formative feedback. Review of Educational Research. 78, 153-189. https://doi.org/10.3102/0034654307313795

Thomas, P.A., Kern, D.E, Hughes, M.T. \& Chen, B.Y. (2016). Curriculum development for medical education: A six-step approach, $3^{\text {rd }}$ ed. Johns Hopkins University Press, Baltimore.

Van der Kleij, F. M., Feskens, R. C. W., \& Eggen, T. J. H. M. (2015). Effects of feedback in a computer-based learning environment on students' learning outcomes: A meta-analysis. Review of Educational Research. 85, 475-511.

Ward, E.C., Baker, S.C., Wall, L.R., Duggan, B.L., Hancock, K.L., Bassett, L.V., \& Hyde, T.J. (2014). Can human mannequin-based simulation provide a feasible and clinically acceptable method for training tracheostomy management skills for speech-language pathologists? American Journal of Speech-Language Pathology, 23, 421-436.

Wiet, G.J., Stredney, D., Wan, D. (2011). Training and simulation in otolaryngology. Otolaryngologic Clinics of North America, 44(6), 1333-1350.

Zendejas, B., Wang, A.T., Brydges, R., Hamstra, S.J., \& Cook, D.A. (2013). Cost: The missing outcome in simulation based medical education research: A systematic review. Surgery, 153(2), 160-176.

Zim, A., Small, S.D., \& Wolpe, P.R. (2000). Patient safety and simulation-based medical education. Medical Teacher, 22(5), 489-495.

Zraick, R.L., Allen, R.M., \& Johnson, S.B. (2003). The use of standardized patients to teach and test interpersonal and communication skills with students in speech-language pathology. Advances in Health Sciences Education, 8, 237-248. 


\section{Appendix A}

Asynchronous and Synchronous Simulation: A Scaffolded Case Study

\section{Case History Information}

The patient, Jeremy Dunkle, is a 73-year-old male who presented to the Emergency Department (ED) via EMS post a fall at home. The patient is known to this facility secondary to a history of repeated falls at home. The patient complained of left hip and thigh pain. Per the radiologist's report, X-rays completed in the ED confirmed a displaced femoral neck fracture of the left hip. The patient was admitted to the hospital and underwent an open reduction internal fixation (ORIF) of the left hip. The patient's past medical history is significant for arthritis, osteoporosis, urinary tract infections, spinal stenosis, frequent falls, and Parkinson's disease. The patient lives at home with and is the primary caretake for his wife who is questionable for early dementia. The patient has two sons, both of whom live out of state. You have been consulted to complete a clinical swallow examination.

\section{Initial Simulated Scenario Objectives}

After completion of the asynchronous and synchronous simulation activities, the students will:

1. Conduct a clinical swallow evaluation (CSE) and show evidence for clinical decision making when using an individualized sequence approach

2. Make diet consistency recommendation considering the findings from the CSE, as well as other patient factors to include cognition, independence during PO intake, general health status, i.e., respiratory status, etc.

3. Make referrals for appropriate services/evaluations

4. Communicate findings and recommendations to the patient and his/her family and to answer related questions

5. Professionally and accurately communicate/collaborate with other health care providers using the SBAR framework

\section{Initial Simulated Scenario Outline}

I. Preparation for the Evaluation

a. Review of the physician's order (synchronous simulation)

b. Review of electronic medical record information (asynchronous and synchronous simulation)

\section{Communication}

a. Consult with the patient's nurse (synchronous simulation)

III. Completion of the Clinical Swallow Evaluation

a. Donning of personal protective equipment if indicated (synchronous simulation)

b. Patient safety and privacy measures (synchronous simulation)

c. Patient interview (asynchronous and synchronous simulation)

d. Cranial nerve-focused oral motor mechanism examination (asynchronous and synchronous simulation)

e. Clinical swallowing evaluation (asynchronous and synchronous simulation)

IV. Analysis of the Evaluation

a. Diagnosis (asynchronous and synchronous simulation)

b. Diet consistency recommendations (asynchronous and synchronous simulation)

c. Referrals (asynchronous and synchronous simulation)

i. Modified Barium Swallow Study (MBSS)

V. Development of a Care Plan

a. Creation of specific, measurable, achievable, realistic, and timely (SMART) dysphagia goals (asynchronous simulation)

\section{Communication}

a. Patient education counseling regarding the results, recommendations, and referrals (synchronous simulation)

b. SBAR communication with the nurse regarding results, recommendations, and referrals (synchronous simulation) 


\section{Scaffolded Simulated Scenario Objectives}

After completion of the asynchronous and synchronous simulation activities, the students will:

1. Conduct a MBSS and show evidence for clinical decision making with respect to appropriate compensatory strategies to trial under instrumentation

2. Make diet consistency recommendation considering the findings from the MBSS, as well as other patient factors to include cognition, independence during PO intake, general health status, i.e., respiratory status, etc.

3. Make referrals for appropriate services/evaluations

4. Communicate findings and recommendations to a patient and his/her family and to answer related questions

5. Professionally and accurately communicate/collaborate with other health care providers using the SBAR framework

\section{Scaffolded Simulated Scenario Outline}

I. Preparation for the Evaluation

a. Review of physician's order (synchronous simulation)

b. Review of electronic medical record for nursing and physician updates (asynchronous and synchronous simulation)

\section{Communication}

a. Communication with the patient regarding purpose and procedures of the evaluation (synchronous simulation)

b. SBAR communication with the radiologist regarding reason for the MBSS referral (synchronous simulation)

III. Completion of the MBSS

a. Administration of consistencies (asynchronous and synchronous simulation)

b. Trial of compensatory positions, strategies, and/or maneuvers (asynchronous and synchronous simulation)

IV. Analysis of the Evaluation

a. Diagnosis (asynchronous and synchronous simulation)

b. Diet consistency recommendations (asynchronous and synchronous simulation)

c. Referrals (asynchronous and synchronous simulation)

V. Development of a Care Plan

i. Gastroenterology consult

a. Addition/modification of the specific, measurable, achievable, realistic, and times (SMART) dysphagia goals to the patient's existing plan of care (asynchronous simulation)

\section{Communication}

a. Patient education counseling regarding the results, recommendations, and referrals (synchronous simulation)

b. SBAR communication with the nurse regarding results, recommendations, and referrals (synchronous simulation) 


\section{Appendix B}

\section{SPEECH-LANGUAGE PATHOLOGY SIMULATION CLINIC RATING SCALE}

Use the following scale to assess student performance on the primary competency areas listed below. Check current level given past clinical experiences.

\begin{tabular}{|l|l|}
\hline$\square$ Novice/Intermediate Level & $\mathbf{X}$ Advanced Level \\
5=Superior performance. Demonstrated independence & 5= Superior performance. Demonstrated independence \\
with initial guidance. & and initiative \\
4=Performed well. Needed general and some specific & 4=Performed well. Needed general direction. \\
direction. & 3=Performed satisfactorily. Needed general and some \\
3=Performed satisfactorily. Needed specific direction. & specific direction \\
2=Below average performance. Needed extensive & 2=Below average performance. Needed specific \\
specific direction. Remediation required. & direction. Remediation required. \\
$\begin{array}{l}\text { 1=Unacceptable performance. Unable to change } \\
\text { performance despite specific direction. Remediation } \\
\text { required. }\end{array}$ & $\begin{array}{l}\text { =Unacceptable performance. Unable to change } \\
\text { performance despite specific direction. Remediation } \\
\text { required. }\end{array}$ \\
\hline $\begin{array}{l}\text { Novice = first clinic } \\
\text { Intermediate = second clinic }\end{array}$ & $\begin{array}{l}\text { Advanced = third and fourth clinics and full-time } \\
\text { internships }\end{array}$ \\
\hline
\end{tabular}

Guidelines for Grading Clinical Competencies:

1. Any item with a score of 2 or lower $(\leq 2)$ requires remediation.

2. Each section should be averaged for a "section average."

3. A student will be considered not passing their clinical competency if

a. The average score for any section is less than $3 \mathrm{OR}$

b. 4 or more items on the entire grading form require remediation

4. You must pass clinical competencies and receive a passing grade to pass your clinical enrollment. Graduate students must have a $\mathrm{B}$ or better to pass the clinic. Clinical hours accrued in a clinic in which the student earns a grade of $\mathrm{C}$ or lower will not count toward the ASHA requirement of 375 clinical clock hours.

5. Totaling all item scores and then dividing by the total number of items graded (i.e., the average) will calculate grade/score on the clinical competency. The grading scale is as follows. Plus/minus grading gives more specificity in feedback regarding a student's clinical competence; however, letter grades without plus/minus will be submitted as per IUP's grading policies.

\begin{tabular}{|l|l|}
\hline $4.5-5.0$ & $\mathrm{~A}$ \\
\hline $4.25-4.49$ & $\mathrm{~A}-$ \\
\hline $4.0-4.24$ & $\mathrm{~B}+$ \\
\hline $3.75-3.99$ & $\mathrm{~B}$ \\
\hline $3.5-3.74$ & $\mathrm{~B}-$ \\
\hline $3.25-3.49$ & $\mathrm{C}+$ \\
\hline $3.0-3.24$ & $\mathrm{C}$ \\
\hline $2.75-2.99$ & $\mathrm{C}-$ \\
\hline
\end{tabular}

Check disorders and age groups treated during this clinical experience:

\begin{tabular}{|l|l|}
\hline Disorders Treated: & Age Groups Treated: \\
$\square$ Articulation & $\square$ Infant/Toddler \\
$\square$ Fluency & $\square$ Preschool \\
$\square$ Voice/resonance & $\square$ School Age \\
$\square$ Receptive/expressive language & $\square$ Adult \\
$\square$ Hearing & $\square$ Geriatric \\
$\square$ Swallowing & \\
$\square$ Cognition & \\
$\square$ Social aspects & \\
$\square$ Communication modalities & \\
\hline
\end{tabular}


The specific competencies and dispositions in this evaluation tool must be demonstrated by the student as appropriate to the clinical experience and the experience level of the clinician. If a student does not demonstrate a competency or disposition, a remediation plan must be developed and implemented so that it is demonstrated prior to graduation. The competencies in this clinic allow the student to meet the following accreditation and certification standards:

\begin{tabular}{|c|c|c|c|}
\hline Course Objectives & $\begin{array}{c}\text { COE-ET Graduate } \\
\text { Framework }\end{array}$ & ASHA Standards & Performance Indicator \\
\hline Competencies I-IV & Practice & IV B-H, V A-B & Competency rankings \\
\hline
\end{tabular}

Communication Skills

Did the student demonstrate adequate knowledge or skill in these areas appropriate for this point in their clinical development?

1. Provides counseling regarding swallowing disorders to the patient, family, caregivers and relevant others.

2. Communicates effectively and appropriately in person, by phone, and in written form considering the needs and cultural values of the listener/reader.

3. Demonstrates understanding of effect of nonverbal communication, i.e., therapeutic touch, body positioning, etc.

4. Demonstrates respect for a "patient's" right to make decisions regarding his/her care through communication of options and associated risks.

5. Demonstrates understanding of and ability to communicate information pertaining to the speechlanguage pathologist's scope of practice.

6. Writes and speaks using Standard American English at an appropriate level.

7. Oral and written communication are free of errors in grammar and/or word choice.

8. Written communication conforms to the standards of the clinical site and the intended audience. Proof-reads documents prior to submission.

9. Follows communication framework guidelines and template guidelines and/or knows when and how to deviate from routine format of reports.

10. Completes administrative, legal, and reporting functions necessary to support evaluation and intervention.

Midterm Comments:

Overall Section Average

Final Comments: 


\begin{tabular}{|c|c|c|}
\hline Student's Name: & Supervi & \\
\hline Ability to Conduct Assessments and Treatment & & \\
\hline $\begin{array}{l}\text { Did the student demonstrate adequate knowledge or skill in these areas appropriate for this point in } \\
\text { their clinical development? }\end{array}$ & Midterm & Final \\
\hline $\begin{array}{l}\text { 11. Demonstrates effective chart review/extracted pertinent information from electronic medical } \\
\text { record (EMR). }\end{array}$ & & \\
\hline $\begin{array}{l}\text { 12. Demonstrates synthesis of information extracted from the electronic medical record (EMR) to } \\
\text { document a concise history and physical. }\end{array}$ & & \\
\hline $\begin{array}{l}\text { 13. Demonstrates consistent compliance with standard procedures (two-patient identifiers, infection } \\
\text { control, etc.) to ensure "patient" safety. }\end{array}$ & & \\
\hline 14. Demonstrates consistent compliance with standard procedures to ensure "patient" privacy. & & \\
\hline $\begin{array}{l}\text { 15. Selects and administers appropriate evaluation procedures, such as behavioral observations, non- } \\
\text { standardized and standardized tests, and instrumental procedures. }\end{array}$ & & \\
\hline $\begin{array}{l}\text { 16. Interprets, integrates, and synthesizes all information to develop a diagnosis and make } \\
\text { appropriate recommendations for intervention. }\end{array}$ & & \\
\hline 17. Refers "patients" for appropriate services. & & \\
\hline $\begin{array}{l}\text { 18. Develops appropriate intervention plans with measurable and achievable goals that meet the } \\
\text { "patient's" needs. }\end{array}$ & & \\
\hline $\begin{array}{l}\text { 19. Selects appropriate intervention methods and/or demonstrates understanding of the principles of } \\
\text { intervention appropriate for the "patient's" diagnosis. }\end{array}$ & & \\
\hline 20. SOAP notes are completed per supervisor's guidelines. & & \\
\hline $\begin{array}{l}\text { 21. Selects or develops and uses appropriate materials and instrumentation for prevention and } \\
\text { intervention. }\end{array}$ & & \\
\hline $\begin{array}{l}\text { 22. Measures and evaluates the "patient's" performance and progress using objective and subjective } \\
\text { data. }\end{array}$ & & \\
\hline 23. Learns and assimilates information from a variety of sources. & & \\
\hline 24. Solves clinical problems through critical analysis. & & \\
\hline 25. Manages multiple tasks well; is organized. & & \\
\hline 26. Demonstrates improvement from simulation to simulation. & & \\
\hline Overall Section Average & & \\
\hline Midterm Comments: & & \\
\hline Final Comments: & & \\
\hline Ethics and Interaction Skills & & \\
\hline $\begin{array}{l}\text { Did the student demonstrate skill in these areas appropriate for this point in their clinical } \\
\text { development? }\end{array}$ & Midterm & Final \\
\hline $\begin{array}{l}\text { 27. Adheres to professional Codes of Ethics, including those of ASHA, PSHA, and the Pennsylvania } \\
\text { Codes for state licensure. }\end{array}$ & & \\
\hline $\begin{array}{l}\text { 28. Collaborates with other professionals and demonstrates a work ethic of personal discipline and } \\
\text { respect. }\end{array}$ & & \\
\hline $\begin{array}{l}\text { 29. Shows sensitivity and respect for individuals from different backgrounds (including differences } \\
\text { in age, ability/disability status, racial/ethnic background, religion, SES, sexual orientation/gender } \\
\text { identity). }\end{array}$ & & \\
\hline 30. Accepts criticism/feedback in an appropriate manner and uses it to improve skills. & & \\
\hline $\begin{array}{l}\text { 31. Recognizes own strengths, accurately identifies areas for growth, and actively works to improve } \\
\text { skills in areas identified as needing growth. }\end{array}$ & & \\
\hline $\begin{array}{l}\text { 32. Demonstrates ability to maintain confidence, composure and maturity and be adaptable/flexible } \\
\text { in a simulated, clinical environment. }\end{array}$ & & \\
\hline $\begin{array}{l}\text { 33. Complies with facility's policies and procedures regarding attendance, punctuality, timeline } \\
\text { requirements, dress code, and universal precautions. }\end{array}$ & & \\
\hline $\begin{array}{l}\text { 34. Exhibits respect for and uses diplomacy with peers, instructors, "patient," and supervisors. } \\
\text { Offers feedback and resolves disagreements appropriately. }\end{array}$ & & \\
\hline Overall Section Average & & \\
\hline Midterm Comments: & & \\
\hline Final Comments: & & \\
\hline
\end{tabular}

